\title{
RESEARCH OF FATIGUE AND MECHANICAL PROPERTIES AIMg1SiCu ALUMINIUM ALLOYS
}

\author{
Mária Mihaliková', Anna Lišková', Marek Vojtko', Tibor Kvačkaj² \\ 1 Department of Materials Science, Faculty of Metallurgy, Technical University in Košice, Park Komenského 11, \\ 04200 Košice, Slovak Republic, e-mail: maria.mihalikova@tuke.sk, anna.liskova@tuke.sk, marek.vojtko@tuke.sk \\ 2 Department of Metals Forming, Faculty of Metallurgy, Technical University of Košice, Park Komenského 11, \\ 04200 Košice,, Slovak Republic, e-mail: tibor.kvackaj@tuke.sk
}

Received: 2015.10.09

Accepted: 2015.11.14

Published: 2015.12.04

\begin{abstract}
The paper is concerned with an analysis of utility and fatigue properties of industrially produced aluminium alloy, specifically EN AW 6061 (AlMg1SiCu), reinforced with the particles of $\mathrm{SiC}$. The following properties were subject to evaluation: microstructure and sub-structure, mechanical characteristics. All of these mechanical properties in pre- and post- equal channel angular pressed (ECAP) state have been studied. The hardness was evaluated by Vickers hardness test at the load of HV10. The significant part the thesis was devoted to the fatigue properties at cyclic load in torsion. The presented results demonstrate well that the combination of fractography and microscopy can give a significant contribution to the knowledge of initiation and propagation crack in the aluminium alloy.
\end{abstract}

Keywords: aluminum alloys, mechanical properties, fractography, hardness, equal channel angular pressing (ECAP), fatigue testing.

\section{INTRODUCTION}

Aluminum alloys belong to the materials which are mostly used in aircraft and automotive industry with a requirement for fatigue resistance of the material [1]. Due to alloying, selected aluminum alloys have a good formability, mechanical properties, weldability and corrosion resistance, but on the other side, they have a low fatigue resistance $[2,3,10]$. Fatigue damage makes $75 \%$ of all damages of the construction materials [4]. The factors which influence fatigue resistance of the material are type and frequency of load, treatment, shape, and surface quality or other stress concentrators of material and influence of the environment where the material is located [5]. Most of the published articles [6-8] dealt with fatigue properties during bending and tensile load. Therefore, torsion fatigue properties of the alloys are analyzed in this article. Representing one of severe plastic deformation methods, the ECAP is intensively concentrated on the development of ultrafined and nanosized grains of metallic and non-metallic materials [9-12]. To achieve such grain parameters, it is essential to resolve not only research problems related to physical metallurgy, construction of equipment for SPD (Several Plastic Deformation), tribology etc., but also dealing with the synthesis of knowledge leading to industrial realization of materials with high physical and mechanical properties [13-15].

In this paper we focused on the study of aluminum alloys of type 6XXX that is mainly alloyed by $\mathrm{Mg}$, Si and the matrix of composite material was aluminium alloy EN AW 6061. As reinforcements, $\mathrm{SiC}$ particles were used.

\section{MATERIALS AND EXPERIMENTAL}

As experimental material was used, the aluminium alloy EN AW 6061on the basic of ALMg1SiCu which was reinforced by $\mathrm{SiC}$ particles. In the initial state, the alloy was treated 
with T4 (heat treatment) solution annealing and naturally aging. The alloy was then subjected to intensive plastic deformation by heat treatment: $\mathrm{T} 4$ solution annealing $540{ }^{\circ} \mathrm{C} / 1.5 \mathrm{~h}+1 \mathrm{x}$ ECAP + artificial aging of $180^{\circ} \mathrm{C} / 8 \mathrm{~h}$. The chemical composition of aluminium alloy, reinforced by $\mathrm{SiC}$ particles and prepared by powder metallurgy is shown in Table 1 [13].

Mechanical properties (yield strength - YS, ultimate tensile strength - UTS, elongation A5 and contraction - Z) were measured by uniaxial tensile test carried out by ZWICK 1387 machine according to STN EN ISO 6892-41 [14]. Young modulus was measured by using the extensometer WN2 52497. Hardness was estimated in a cross-section by the Vickers test. Results of mechanical properties evaluated as average value from six measurements are summarized in Table 2.

It is possible to estimate that the mechanical properties are most dependent on the intensity of plastic deformation (ECAP). The highest YS and UTS were measured for EN AW 6061 after Equal Channel Angular Pressing, which led to the highest strain hardening. On the contrary, the aluminium alloys, which were treated by $\mathrm{T} 4$ processing show significant differences in plasticity are found out in aluminum composite. The sam- ples for observation by light microscopy were prepared by metallographic procedure. Samples etching were carried out by Kroll solution (92 $\mathrm{ml}$ distilled water, $6 \mathrm{ml} \mathrm{HNO}_{3}$, and $2 \mathrm{ml} \mathrm{HF}$ ). Microstructures are documented in Figure 1 by an optical microscope OLYMPUS VANOX-T.

Thin foils for transmission electron microscopy (TEM - Jeol JEM 200 FX operated at $200 \mathrm{kV}$ ) observation were prepared by double jet electropolishing in TenuPol -5 at voltage $15 \mathrm{~V}$. Solution of $33 \% \mathrm{HNO}_{3}$ and $67 \% \mathrm{CH} 3 \mathrm{OH}$ was used as an electrolyte. The structures have been observed by TEM in the bright field images which are shown in the Figure 2.

The observed dislocation density and grain size of materials confirmed the assumption that the mechanical properties are highly dependent on the ECAP process. The highest dislocation density and the lowest grain size were observed in post - ECAP state.

Specimens for fatigue tests were prepared by turning machine in a form of rods with sizes 35.8 $\times 7.95 \times 6.00 \mathrm{~mm}$. Torsional fatigue was carried out by HENCK PWO 0298 machine. The failure values are displayed in semi-logarithmic plot of Wöhler curve in Figure 3 which indicates nonexistence of the endurance limit typical for aluminum alloys.

Table 1. Chemical composition of aluminum alloys [wt. \%]

\begin{tabular}{|c|c|c|c|c|c|c|c|}
\hline Material & $\mathrm{Al}$ & $\mathrm{Si}$ & $\mathrm{Mg}$ & $\mathrm{Zn}$ & $\mathrm{Mn}$ & $\mathrm{Cu}$ & $\mathrm{Fe}$ \\
\hline EN AW 6061 & 95.35 & 0.40 & 0.80 & 0.25 & 0.15 & 0.15 & 0.70 \\
\hline
\end{tabular}

Table 2. Mechanical properties of aluminium alloys

\begin{tabular}{|l|c|c|c|c|c|c|c|c|}
\hline \multicolumn{1}{|c|}{ Material } & YS [MPa] & UTS [MPa] & A $_{5}[\%]$ & Z [\%] & E [GPa] & HV $10\left[{\left.\mathrm{~N} . m^{-2}\right]}_{1}\right.$ HV $30\left[N \cdot m^{-2}\right]$ & YS/UTS \\
\hline EN AW 6061 & 205 & 274 & 9 & 9 & 110 & 88 & 80 & 0.74 \\
\hline EN AW 6061 (ECAP) & 356 & 363 & 6 & 8 & 100 & 125 & 120 & 0.98 \\
\hline
\end{tabular}

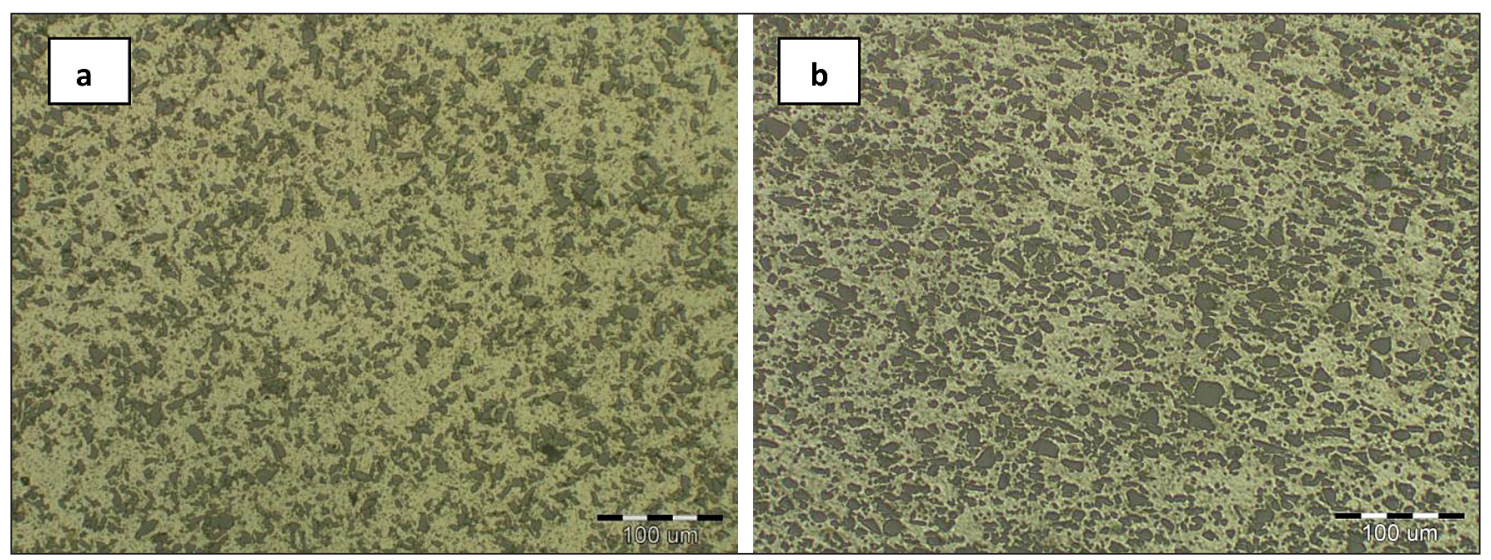

Fig. 1. Microstructures of the composite EN AW 6061 (a) and alloys EN AW 6061 post ECAP state (b) 


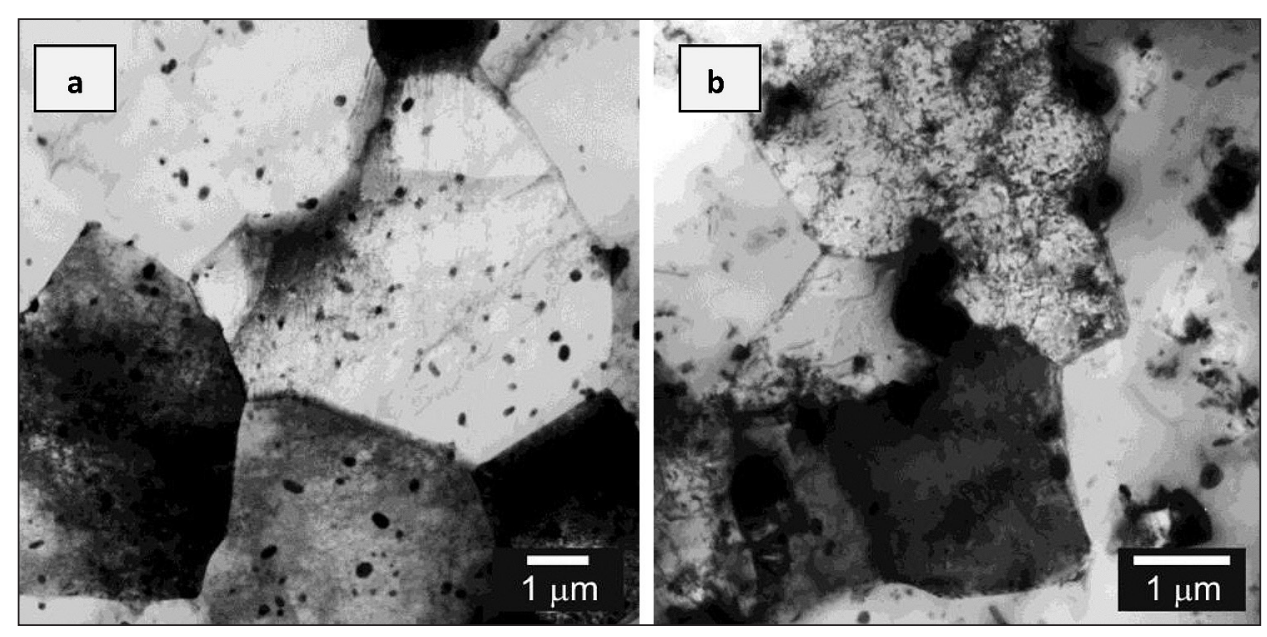

Fig. 2. Microstructures EN AW 6061 observed by TEM, a) pre - ECAP, b) post - ECAP

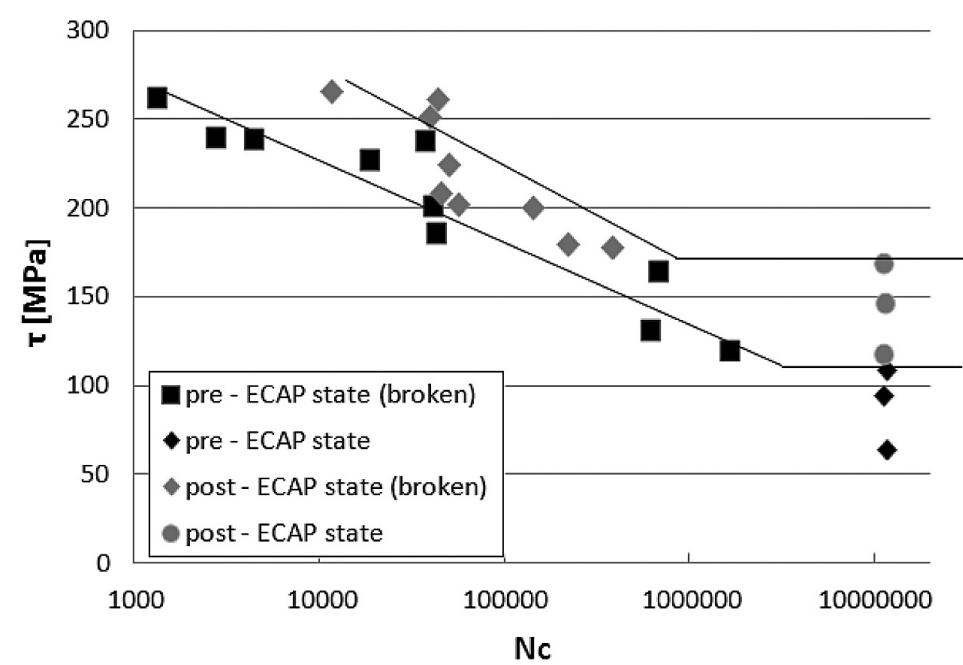

post - ECAP state

$\tau \mathrm{C}= \pm 155 \mathrm{MPa}$

pre- ECAP state

$\tau \mathrm{C}= \pm 115 \mathrm{MPa}$

Fig. 3. Wöhler curve of EN AW 6061 aluminium alloys

On the basis of a slope of diagonal branch Wohler curve can be noted the highest crack initialization resistance of EN AW 6061 alloy. The lowest resistance was detected on the composite EN AW 6061, which is related with ductility reduction of the alloy. Figue $4(a, b)$ shows the nature of samples breach during cycle loading in torsion for selected types of aluminium alloys.

This breach occurred in the application of stress: $132 \mathrm{MPa}$ for the pre - ECAP aluminium alloys and $179 \mathrm{MPa}$ for the post - ECAP EN AW 6061 composite. Fracture surface documented in Figure 4. Surface of fracture on the each sample EN AW 6061 composite took place in the direction of load axial.

Fraction areas of the observed alloys were assessed by SEM Jeol JSM-7000F. Fraction surfaces, documented by SEM, are shown in Figure 5 and Figure 6 . Figure $5(\mathrm{a}, \mathrm{b})$ shows fracture fatigue surface which can be divided into three characteristic areas: place of initialization, stable crack growth, and final rupture. Initialization of the fracture started from the surface of specimen and the crack growth continues in perpendicular direction of the specimen axis. The morphology of fracture surface was observed as characterized dimples with local presence of striation. Fine grained morphology was observed in the composite EN AW 6061.

Figure 6(a,b) shows fracture surfaces of the composite EN AW 6061 in post - ECAP state. The fracture surface appeared distinguishable and regularly occurring characters, the council of parallel traces are the result of stiffening particles, in this case $\mathrm{SiC}$ particles, protruding from the crack and the imprint in the surface of the material. The movement of these particles carries shear mechanism. 


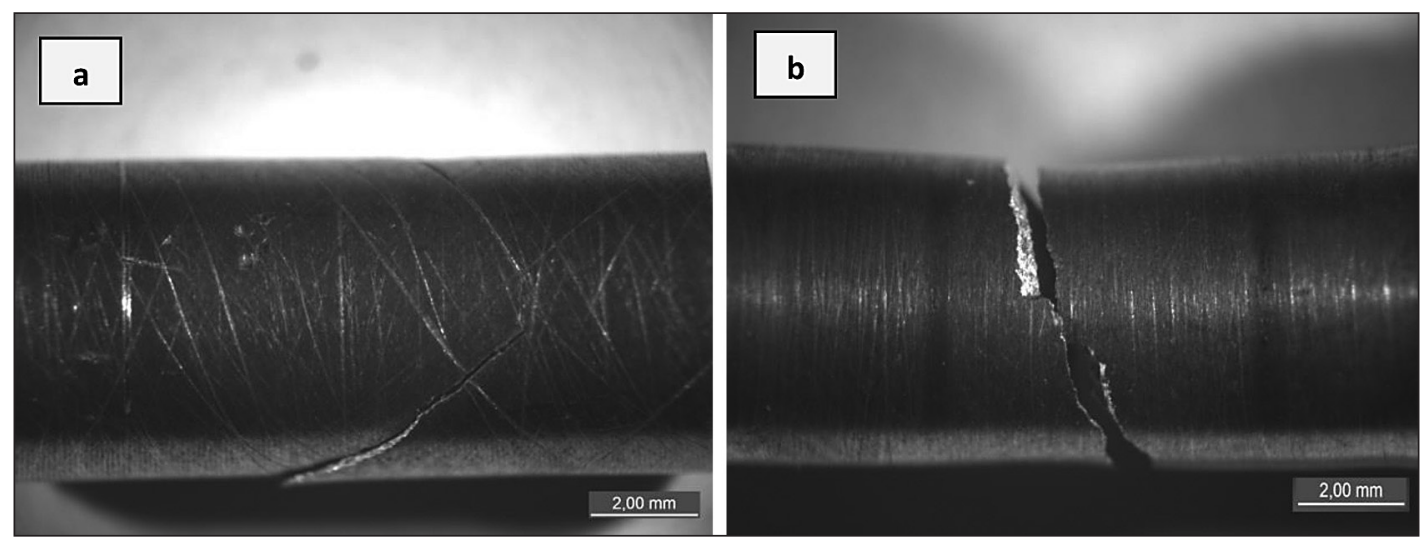

Fig. 4. Fatigue fracture of the composite EN AW 6061 (a) pre - ECAP (b), post - ECAP

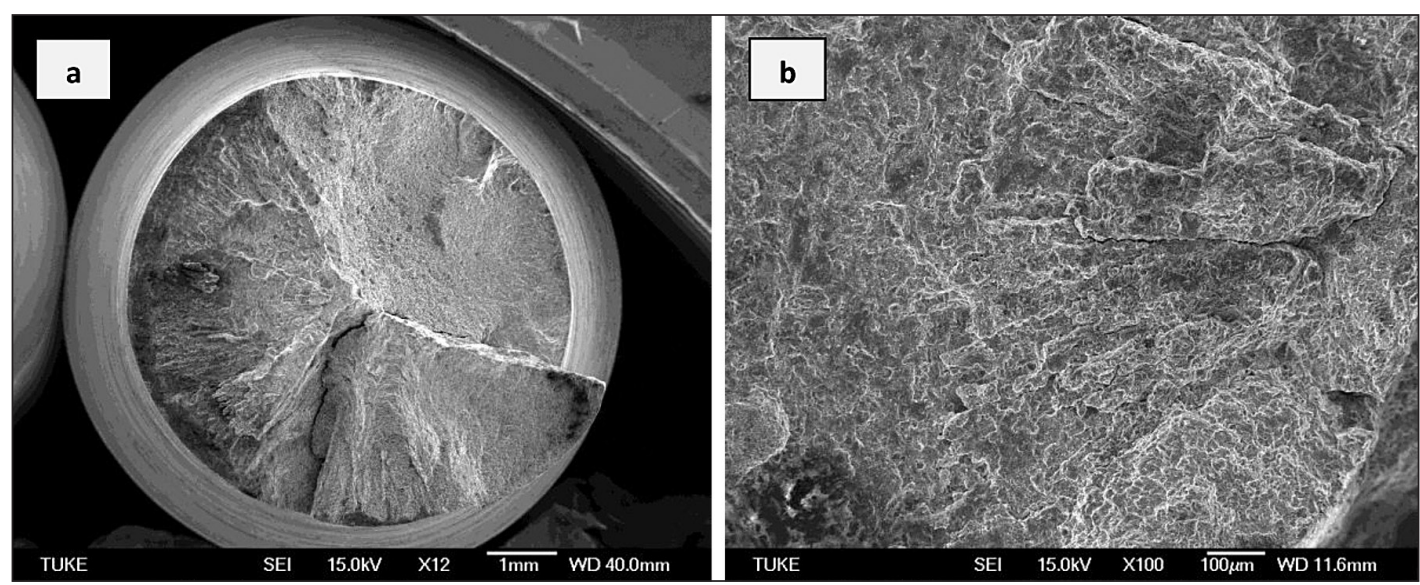

Fig. 5. Fracture surfaces of the composite EN AW 6061 (a) and detail fracture (b)
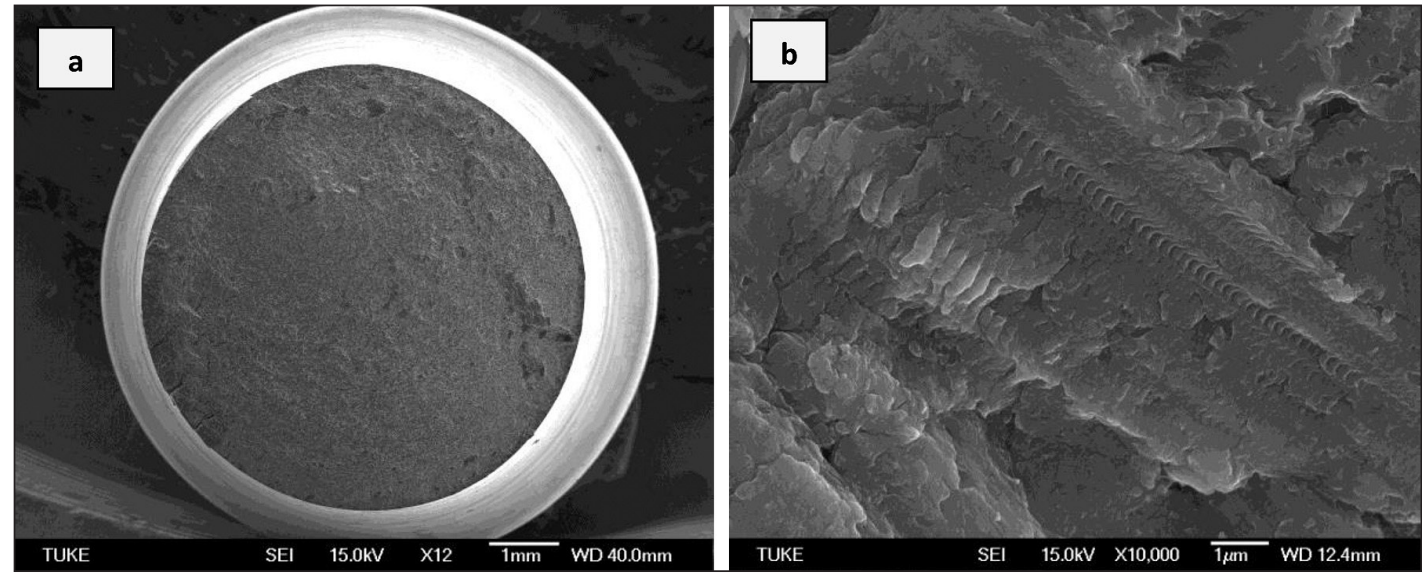

Fig. 6. Fracture surfaces of the composite EN AW 6061 post - ECAP state (a) and detail (b)

\section{CONCLUSIONS}

Based on the results of the experimental part, it is possible to note the following:

1. Treatment procedures and chemical composition of the three industrially fabricated aluminum alloys caused to strong differences of strength properties (i.e. YS in the range from 185 to $281 \mathrm{MPa}$ ) and plasticity ( $7 \%$ to $12 \%)$.
2. The highest crack initialization resistance was found out on the alloy EN AW 6061 in ECAP state and the lowest in the composite EN AW 6061.

3. Fracture surface is perpendicular of the load on the EN AW 6061 in ECAP state alloy and EN AW 6061 in ECAP state alloy, too. Surface of fracture on the EN AW 6061 composite took place in the direction of load axial. 
4. The flat fracture with dimples and local presence of striations was observed on the EN AW 6061 alloys. The composite EN AW 6061 had highly fractal fracture with fine grained morphology.

5. The grain size and dislocation density of aluminum alloys were observed by TEM and the observation proved that the mechanical properties (especially YS/UTS) of alloys are most dependent on the treatment.

\section{Acknowledgements}

This study was supported by the Grant Agency of Slovak Republic, grant project VEGA 1/0549/14.

\section{REFERENCES}

1. Du Feng-Shan et al. Study on fatigue performance of high strength aluminum alloy. Journal of Aeronautical Materials, 29(1), 2009, 96-100.

2. Enescu C.M. et al.:Experimental researches on the corrosion behavior and microstructural aspects of heat treated Al-Zn-Mg-Cu alloys. International Journal of Energy and Environment, 4, 2010, 122-130.

3. Totten G.E. el al. Handbook of aluminum. In: Physical Metallurgy and Processes, 2003.

4. Daunys M. et al. Low cycle stress curves and fatigue under tension-compression and torsion.
Mechanika, 2009, 5-11.

5. Halfpenny A. Practical Discussion on Fatigue. Environmental Engineering, 14(3), 2001.

6. Ebara R. et al. Environmental Fatigue of 7075-T6 Aluminum Alloy. Engineering Materials, 2011, 13-16.

7. Kariya K. et al. Fatigue fracture mechanism of extruded Al alloy 7075-T6 in high humidity. Engineering Materials, 2012, 45-48.

8. Faltus J. et al. Fatigue properties of machinable aluminium alloys AA2007 and AA2015. Metal, 2006, 1-8.

9. Kvačkaj T. et al. Simulation of ECAP process by finite element method. Kovove Mater., 45, 2007, 249.

10. Spišák E. et al. Effect of the electrolyte temperature and the current density on a layer microhardness generated by the anodic aluminium oxidation. Advances in Materials Science and Engineering, 2015, 9 pages.

11. Valiev R.Z. Nanostructuring of metals by severe plastic deformation for advanced properties. Nature Materials, 3, 2004, 511-516.

12. Valiev R.Z., Langdon T.G. Principles of equal-channel angular pressing as a processing tool for grain refinement. Prog. Mater. Sci., 51, 2006, 881-981.

13. Lukáč I. Heat treating of Aluminium and its alloys. In: Aluminium materials and technologies from $\mathrm{A}$ to Z, 2007, 359-380.

14. STN EN ISO 6892-1 420310:2010. Metallic materials - Tensile testing. Method of test at room temperature. 